\author{
ANNA DI CASTRO Y ANN CYPHERS \\ INSTITUTO DE INVESTIGACIONES ANTROPOLÓGICAS, UNAM
}

\title{
Iconografía de la cerámica de San Lorenzo
}

En memoria de la doctora Beatriz de la Fuente, incansable exploradora del mundo olmeca

$\mathrm{E}$ NTRE LOS OBJETOS CONSIDERADOS olmecas se cuentan las vasijas cerámicas decoradas con motivos incisos o excisos como son la cruz, la $\mathrm{U}$ y la mano-ala-pata (fig. I). En San Lorenzo, Veracruz, estas cerámicas llegan a su máxima frecuencia durante el apogeo de esa capital olmeca, ${ }^{\mathrm{I}}$ del II5O al 850 a.C. En el marco de la polémica que ha surgido en cuanto al origen olmeca de la iconografía y de las vasijas mismas que la portan, ${ }^{2}$ David C. Grove ${ }^{3}$ ha sugerido que los motivos pueden designarse de manera neutral: como el Complejo X, término que carece de connotaciones sobre su afiliación cultural.

I. Michael D. Coe y Richard A. Diehl, In the Land of the Olmec, Austin, University of Texas Press, 1980, vol. I, pp. I62-I70; Ann Cyphers, "La cerámica de San Lorenzo Tenochtitlán”, s.f., ms.

2. Véase Joyce Marcus, "Zapotec Chiefdoms and the Nature of Formative Religions", en Robert J. Sharer y David C. Grove (comps.), Regional Perspectives on the Olmec, Nueva York, Cambridge University Press, 1989, pp. I48-197; Arthur Demarest, "The Olmec and the Rise of Civilization in Eastern Mesoamerica”, en Sharer y Grove (comps.), op. cit., pp. 303-344; Jeffrey P. Blomster et al., "Olmec Pottery Production and Export in Ancient Mexico Determined Through Elemental Analysis", Science, vol. 307, 2005, pp. I068-I072; Kent V. Flannery et al., "Implications of New Petrographic Analysis for the Olmec 'Mother Culture' Model”, Proceedings of the National Academy of Science, vol. I02, núm. 32, 2005, pp. II219-II223; James B. Stoltman et al., "Petrographic Evidence Shows that Pottery Exchange Between the Olmec and their Neighbors Was Two-way", Proceedings of the National Academy of Sciences, vol. IO2, núm. 32, 2005, pp. II2I3-II2I8.

3. David C. Grove, "Olmec: What's in a Name?", en Sharer y Grove (comps.), op. cit., pp. 8-16. 
El presente trabajo tiene la finalidad de ofrecer un análisis formal de los motivos comunes del Complejo X que se presentan en la capital olmeca, San Lorenzo, Veracruz, durante el Preclásico inferior (I350-850 a.C.), y de proporcionar analogías iconográficas con el fin de profundizar en su significado. Además se ofrecen las evidencias que permiten examinar si la simbología de estas vasijas surge de un sustrato ideológico panmesoamericano, ${ }^{4}$ si se originó en la cuenca de México $^{5}$ o en la región de San Lorenzo Tenochtitlán.

Nuestro análisis formal ${ }^{6}$ se centra en los motivos comunes exhibidos en dos tipos cerámicos que caracterizan el periodo Preclásico inferior en San Lorenzo (fases San Lorenzo A y B, II50-850 a.C.). Cabe hacer notar que la nueva clasificación de la cerámica de San Lorenzo ${ }^{7}$ se basa en primer término en la pasta y el acabado de la superficie; la decoración se considera un atributo en lugar de un elemento que define un tipo. Los tipos cerámicos que presentan la mayor frecuencia de esta decoración son Tigrillo Negro y Tigrillo Blanco y Negro, los cuales pueden ostentar la decoración de línea ancha llamada de manera general Calzadas, término adaptado de un tipo cerámico definido por Michael D. Coe y Richard A. Diehl. ${ }^{8}$ Por lo común, estas cerámicas se distinguen por una superficie pulida de color: a) negro a grisáceo o b) blanco y negro (logrado por la cocción diferencial controlada), respectivamente.

A través del análisis formal de los motivos y su comparación con la cerámica del Altiplano Central y Oaxaca, los monumentos pétreos y elementos mesoamericanos más tardíos, se intentará aproximarse a sus posibles significados. También se examinará la cuestión de su temporalidad.

\section{El análisis formal de los diseños Calzadas}

La decoración Calzadas se distingue por su carácter geométrico y su amplitud. Al calificarla de geométrica abstracta en cierto sentido se están encasillando

4. Demarest, op. cit:; Robert J. Sharer, "The Olmec and the Southeast Periphery of Mesoamerica”, en Sharer y Grove (comps.), op. cit., pp. 247-27I; Marcus, op. cit.; Grove, op. cit.

5. Kent V. Flannery y Joyce Marcus, "Formative Mexican Chiefdoms and the Myth of 'Mother Culture”, Journal of Anthropological Archaeology, núm. 19, 2000, pp. I-37.

6. Véase también Anna Di Castro, "Estudio iconográfico de la cerámica olmeca de San Lorenzo, Veracruz", tesis de maestría en Estudios Mesoamericanos, México, Universidad Nacional Autónoma de México-Facultad de Filosofía y Letras, 2005.

7. Cyphers, op. cit.

8. Coe y Diehl, op. cit. 
estas representaciones dentro del binomio naturalista/figurativo-abstracto. El contraponer estas categorías proviene del esquema evolucionista del siglo XIX pues se consideraba que la reproducción figurativa fue el primer paso de la trayectoria unilineal de la evolución del arte que desembocó en el arte abstracto. Sin embargo, algunos autores, como José Alcina Franch, califican la geometrización - a la que consideran una forma de abstracción — como una simplificación de la realidad a sus líneas esenciales, lo cual a veces constituye una necesidad debido al material usado, como sucede por ejemplo en la cestería y el tejido. ${ }^{9} \mathrm{La}$ abstracción implica un proceso mental en el que se desvía, se desintegra y se deconstruye la realidad; una forma de percibir el mundo en la que ya no hay una comunión entre lo humano y el exterior. Con respecto a esta discusión, André Leroi-Gourhan apunta un hecho importante sobre la prehistoria europea: "que el grafismo no comienza por una expresión servil y fotográfica de lo real, sino se le ve organizarse en el curso de una decena de miles de años a partir de signos que parecen haber expresado primero unos ritmos y no unas formas", ${ }^{\text {io }}$ idea que retomaremos más adelante.

Lo más común es que la representación geométrica y la figurativa coexistan en una misma cultura con gradaciones, desde lo completamente abstracto hasta las representaciones que tratan de imitar la realidad tal como se percibe. Sin embargo, la percepción de la realidad se subordina a una forma cultural de ver, ya que "de los hechos, eventos, acontecimientos, objetos, el mundo en general, tenemos acceso solamente a sus representaciones, las cuales son siempre construcciones, pues no hay fenómenos naturales en estado bruto". ${ }^{I I} \mathrm{Un}$ ejemplo que conviene mencionar porque ilustra claramente esta situación es el caso de los indios tukano de Colombia. ${ }^{12}$ Los integrantes de este grupo étnico decoran objetos con las imágenes geométricas que vieron durante las visiones producidas por el alucinógeno yajé, las cuales, más que simples decoraciones, son símbolos o fragmentos de discursos mitológicos. Este ejemplo sirve para mostrar la relatividad de las percepciones visuales y la ambigüedad del término realismo, ya que — si consideramos como realidad lo que percibimos a través

9. José Alcina Franch, Arte y antropología, Madrid, Alianza, 1988, pp. II3-I26.

Io. André Leroi-Gourhan, El gesto y la palabra, Felipe Carrera (trad.), Caracas, Biblioteca de la Universidad Central de Venezuela, I97I, p. I88.

II. César González Ochoa, Imagen y sentido. Elementos para una semiótica de los mensajes visuales, México, Universidad Nacional Autónoma de México-Instituto de Investigaciones Filológicas, 1986, p. 9 .

I2. Alcina Franch, op. cit., pp. 29-35. 
de la vista - la visión humana se construye y se puede considerar un artefacto histórico y cultural, creado y transformado por los procesos biopsicosociales que intervienen en el proceso de representación. En el caso de los fosfenos o imágenes entópticas como las de los tukano, las figuras producidas detrás de la retina son comparadas con experiencias grabadas en la memoria del individuo, y si éste logra asociarlas con algo conocido reconocerá en ellas una imagen. Por lo anterior, las categorías figurativo-abstractas son solamente figuras de dicción, a las cuales es inevitable recurrir para describir un diseño, sin valorar el proceso intelectual implicado en el proceso creativo.

En el caso de la decoración Calzadas, su carácter geométrico y abstracto ha sido considerado la representación del todo por sus partes desde que Miguel Covarrubias $^{13}$ expuso que "el dios jaguar 'olmeca' se desintegraba frecuentemente en las partes que lo componían: la máscara, o rasgos aislados tales como los ojos vacíos, las cejas en forma de sierra, la boca, una cruz y una mano humana. El resultado en los diseños era tan abstracto que no debe haber tenido significado más que para los iniciados"; posteriormente a esta desintegración minimalista se le llamó pars pro toto. ${ }^{\mathrm{I4}}$

Otra característica de la decoración Calzadas son las incisiones muy amplias, excavadas, parecidas a la de los sellos, que le imprimen un juego de claroscuros a la vasija y un carácter cuasi escultural, una dimensión y un fuerte contraste tanto por la incidencia de la luz sobre los diferentes niveles de la superficie como por la textura áspera de la base de la parte excavada contra la superficie pulida y más iluminada de la vasija. Seguramente las incisiones se elaboraron con un objeto de punta plana rectangular, como se aprecia en los extremos de las secciones excavadas. El contraste es una característica fundamental, ya que es la fuerza que hace más visibles las estrategias compositivas. ${ }^{15}$ Pareciera como si la intención del artesano olmeca hubiera sido la de imprimir el sentido del diseño en el corazón mismo del barro, dándole el "ser" a la vasija, un soplo de vida. $\mathrm{Al}$ igual que el sentido del tatuaje en el cuerpo humano, las profundas incisiones de la decoración resignifican a la vasija más allá de su valor funcional.

13. Miguel Covarrubias, Arte indígena de México y Centroamérica, México, Universidad Nacional Autónoma de México, 1961, p. 66.

I4. Michael D. Coe, "Early Steps in the Evolution of Maya Writing", en H.B. Nicholson (comp.), Origins of Religious Art and Iconography in Preclassic Mesoamerica, Los Ángeles, University of California (Latin American Studies Series, 3I), I976, p. III.

I5. Donis A. Dondis, La sintaxis de la imagen. Introducción al alfabeto visual, México, Gustavo Gili, 2002, p. I28. 
Un importante rasgo de la decoración Calzadas, en cuanto al espacio que cubre, es que con pocos trazos, amplios y profundos, logró el efecto de expansión y nitidez por medio del juego entre profundidad, longitud y espesor de la incisión. Algunas vasijas sólo presentan un diseño en una pequeña área pero, por las características antes mencionadas, éste produce un efecto visual mucho mayor, ya que resalta en el vacío; desde nuestra perspectiva actual, hay un fuerte contraste entre la sencillez del diseño y la complejidad de su significado, como si ese único motivo contuviera tanto poder o sentido que la vasija no pudiera albergar otro, situación muy diferente a la de composiciones un poco más tardías del Altiplano que utilizan motivos similares, aunque combinados.

La ocasional presencia de pigmento rojo en la base de las incisiones es un dato que podría indicar que los motivos tenían un carácter sagrado. La coincidencia geométrico-roja, en contraste con la naturaleza sinuosa de la decoración estilo Limón, ofrecería la oposición de contrarios que con frecuencia está presente en la cosmovisión de varias culturas prehispánicas posteriores a los olmecas y grupos indígenas actuales, como se observa por ejemplo en los glifos de la insignia tripartita, en los que están a cada lado del pájaro y del monstruo celestes en la iconografía maya y en la concepción del mítico Chicomóstoc que se muestra en la Historia tolteca-chichimeca. ${ }^{16}$

Mediante la clasificación por semejanza formal de los diseños presentes en tiestos y vasijas completas y semicompletas, se pueden aproximar los diseños presentes en el sitio de San Lorenzo a lo largo de su ocupación. Para estudiar las cualidades formales de la decoración Calzadas se utilizaron las siguientes unidades analíticas: elemento, motivo, configuración del diseño (ubicación de motivos, subdivisión de áreas, espacio cubierto), relación entre las unidades y simetría. Obviamente estas unidades analíticas no necesariamente corresponden a las unidades conceptuales que el artista tenía en la mente al llenar el espacio del diseño. Seguramente, en el momento de la ejecución se pensó en la configuración como un todo, ya que cada motivo parece ocupar un lugar particular, como si se siguieran las reglas de una sintaxis específica.

A pesar de que esta metodología aparentemente sólo es una forma de ordenar los diseños, su intención es poder elaborar inferencias sobre la sociedad que utilizó y produjo esta decoración; es necesario relacionar sociedad con estilo, ir más

I6. Paul Kirchhoff et al., Historia tolteca-chichimeca, 2a. ed., México, Centro de Investigaciones y Estudios Superiores en Antropología Social / Fondo de Cultura Económica (Colección Puebla), 1989 . 
allá de las cualidades o forma y desentrañar su contenido o significado, ya que el estudio del significado estilístico incluye la manera en que el arte expresa las características o creencias (como las preferencias estéticas conscientes o inconscientes de la comunidad y rasgos sobresalientes del ambiente social y natural) de la sociedad que lo produjo. Además, el particular uso de las imágenes y del espacio en un estilo constituye un código simbólico que refuerza las estructuras sociales y cosmológicas, las creencias y los valores. ${ }^{17}$

Los tres tipos de simetría o movimiento que encontramos en la decoración Calzadas son I) la simetría por traslación, simple repetición serial a lo largo de una línea recta sin cambio en la orientación del elemento, la cual es común en la decoración Calzadas: 2) la simetría bilateral o por reflexión, repetición de un elemento como si se reflejara ante un espejo, de manera vertical, horizontal o diagonal, y 3) la asimetría, un diseño constituido únicamente por una parte fundamental que no se repite o mueve.

La composición asimétrica consiste en una sola figura, generalmente zoomorfa-antropomorfa, que constituye la única decoración de la vasija. Por otro lado, la composición simétrica se caracteriza por presentar un diseño compuesto por elementos que, a partir de la línea recta y a través de traslaciones bilaterales, invertidas y en espejo, conforman los motivos. A su vez, por medio de una operación de traslación, a menudo los motivos se colocaron configurando un diseño que por lo general divide dos espacios longitudinales en el exterior de la vasija: un área superior vacía y un área inferior que contiene los motivos distribuidos rítmicamente a lo largo del espacio. De esta manera, la sección que presenta los motivos parece estar enmarcada por un espacio superior donde sólo el color, ahora perdido, y el volumen constituyen los elementos de la composición, dando como resultado un contraste entre superior-liso e inferior-excavado.

Los cuatro elementos utilizados en la composición incluyen: a) dos bandas cruzadas (fig. Ib), b) la U invertida (fig. Ic), c) las bandas paralelas divergentes (fig. Ia) y d) la cabeza de un ser (fig. Id). A su vez, estos elementos se combinan con otras incisiones accesorias (e.g. ganchos, la ceja flamígera) para configurar los siguientes cuatro motivos populares en San Lorenzo:

I) el de dos bandas cruzadas dispuestas en serie horizontal, de composición simétrica (figs. 2a y $2 \mathrm{~b}$ );

17. Prudence Rice, Pottery Analysis. A Sourcebook, Chicago, University of Chicago Press, I987, p. 251 . 


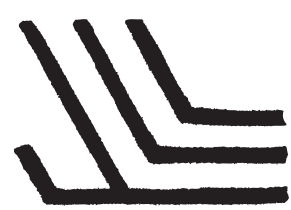

a)

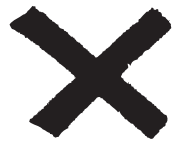

b)

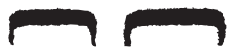

c)

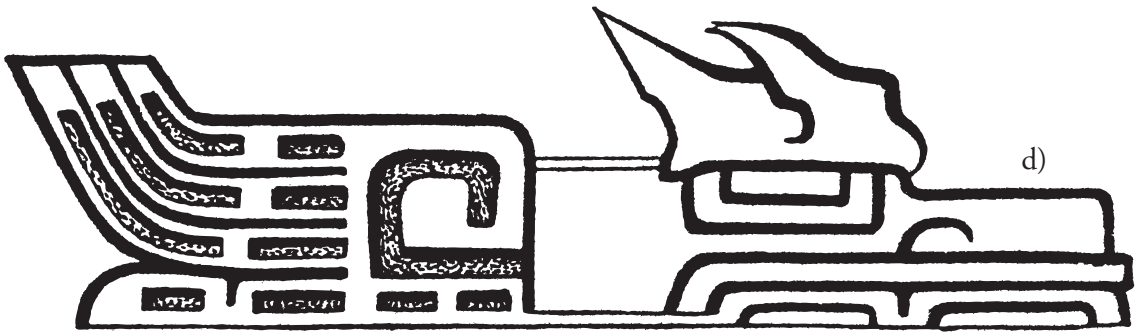

I. Elementos decorativos en la cerámica: a) mano-ala-pata, b) cruz, c) Úes invertidas, d) dragón. Dibujos de Ann Cyphers basados en Miguel Covarrubias, Arte indígena de México y Centroamérica, México, Universidad Nacional Autónoma de México, 1961, p. 35.

2) el de U invertida dispuesta en serie horizontal, de composición simétrica (figs. 2c y 2d);

3) el de bandas paralelas divergentes, de composición simétrica (fig. 2g),

4) y el asimétrico, de una criatura fantástica (fig. 3) compuesta por varios elementos que incluyen la $\mathrm{U}$ invertida, dos bandas cruzadas, las bandas paralelas divergentes hacia arriba, la cabeza con rasgos antropomorfos y zoomorfos, así como otros elementos (i.e. la voluta, la llamada ceja flamígera, entre otros).

El análisis formal conduce a comparaciones y analogías para indagar el significado de los motivos. El puente de inferencia entre lo formal y lo interpretativo no siempre ha sido explícito en la bibliografía sobre la iconografía olmeca; no obstante, a los cuatro elementos antes mencionados se les han aplicado designaciones particulares basadas en diversas analogías y asociaciones; por ello es común observar que se llamen cruz (o cruz de san Andrés), corchete rectangular (o doble línea interrumpida), mano-ala-pata y dragón. En la siguiente discusión se utilizarán estos términos porque son familiares para los interesados en las culturas preclásicas. Además, se puntualizará su presencia en otros contextos y las inferencias sobre su significado. 


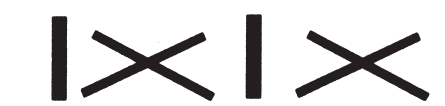

a)

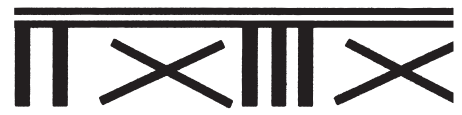

b)

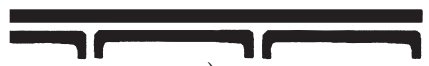

c)

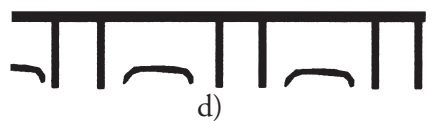

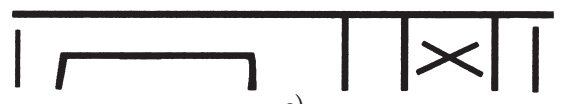

e)

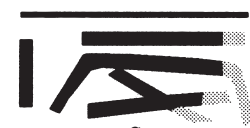

f)

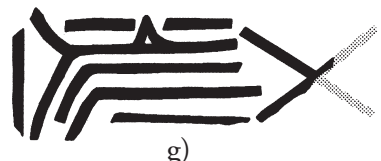

g)

2. Composiciones simétricas: $a-b)$ series horizontales de cruces; $c-d)$ series horizontales de Úes invertidas; e-f) series horizontales que combinan varios elementos; g) mano-ala-pata en composición simétrica con una cruz. Dibujos de Ann Cyphers.

\section{La cruz dispuesta en serie horizontal}

La cruz (las dos bandas cruzadas) es uno de los elementos más discutidos no sólo en los trabajos sobre el tema de las creencias panmesoamericanas, ${ }^{18}$ sino también en los estudios sobre los iconos religiosos mundiales, ya que es uno de los más frecuentes e importantes. Uno de sus principales significados universales es la conjunción, la unión de contrarios. ${ }^{19}$ También figura prominentemente su asociación celeste, de acuerdo con varios autores (tabla i).

En la cerámica de San Lorenzo, este elemento aparece solamente en tiestos, ya que no se cuenta con vasijas completas o parciales que nos muestren su contexto total. Por lo tanto, con base en la evidencia fragmentaria, creemos que la cruz se presenta principalmente en la composición simétrica, en la cual se dispone en una serie horizontal en el lado exterior de la vasija. Tiene dos asociaciones

I8. Peter D. Joralemon, “The Olmec Dragon: A Study in Pre-Columbian Iconography”, en H.B. Nicholson (comp.), op. cit., pp. 27-71; Michael Muse y T. Stocker, "The Cult of the Cross", The Steward Anthropological Journal, vol. 5, núm. 2, 1974, pp. 67-98.

I9. Jorge Angulo, "The Chalcatzingo Reliefs: An Iconographic Analysis", en David C. Grove (comp.), Ancient Chalcatzingo, Austin, University of Texas Press, 1987, pp. 135-136. 


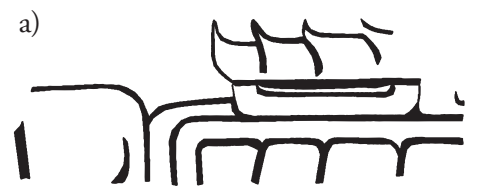

b)

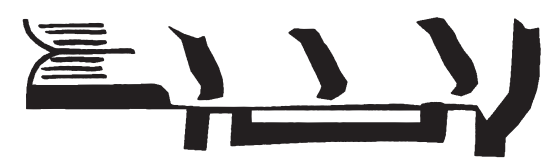

c)

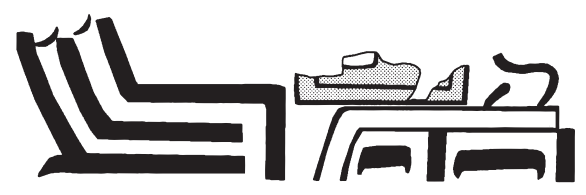

3. Cerámica de la fase San Lorenzo B que muestra el monstruo cósmico: a) una voluta parcial, que probablemente forma parte de un elemento mano-ala-pata localizado del lado izquierdo de la cabeza, la cual se caracteriza por la ceja flamígera, el ojo en forma de U, y las encías en forma de Úes invertidas (redibujado por Michael D. Coe y Richard A. Diehl, In the Land of the Olmec, Austin, University of Texas Press, I980, vol. I, fig. I40i); b) una imagen carente de boca que muestra elementos en forma de plumas en el lugar de la mano-ala-pata, el ojo en forma de U y líneas incisas diagonales en lugar de la ceja flamígera; c) imagen con el ojo en forma de U, la nariz antropomorfa, la boca formada por Úes invertidas y la mano-ala-pata ubicada del lado izquierdo de la cabeza. Dibujos de Ann Cyphers. 
Tabla I. Analogías e interpretaciones de la cruz por varios autores.

\begin{tabular}{ll}
\hline Analogía, interpretación & Autor \\
\hline Deidades del cielo y del inframundo & Angulo 1987: 136 \\
El Sol o cielos de los mayas & Angulo 1987: I4I \\
La Vía Láctea & Angulo 1994: 230 \\
Omaxalli o cruce de caminos & Angulo 1987: 135 \\
Caa (o kaa) significa serpiente y cielo, palabras que son homófonas & Ayala 1968: 93 \\
Glifo T552: signo del cielo e inframundo & Ayala 1968: 92-93 \\
Kan significa cielo & Ayala 1968: 93 \\
El centro del cielo & Reilly 1994: 244 \\
La imaginería celestial & Reilly 1994: 246 \\
Es un motivo polisémico & Joralemon 1976: 47 \\
Está asociado con el autosacrificio & Joyce et al. 1991: 5 \\
La hendidura del caimán o del universo & Muse y Stocker 1974: 85 \\
Glifos kin, uo, zip, B y bandas celestes significan agua, cielo, Sol & Norman 1976: 35 \\
La mancha del jaguar, el Sol, el calor, la luz solar & Piña Chan 2002: 29; \\
& Piña Chan y \\
Cruz de kan o rumbos del universo & Covarrubias 1964: 46 \\
Confiere rasgos serpentinos a criaturas compuestas & Piña Chan 2002: 35 \\
Axis mundi, quincunx, ancestros, protección contra el mal, & Quirarte 1977: 264 \\
límites entre la naturaleza y la cultura, la identidad & \\
política y social colectiva & \\
\hline
\end{tabular}

ligeramente diferentes: a) como una secuencia de cruces intercaladas con una o más líneas verticales que rodean toda la vasija (figs. 2a y 2b) y entre una o dos líneas horizontales que en ocasiones alternan diferente grosor (fig. 2b). También puede presentarse en una serie combinada con la U invertida (fig. 2e) o dentro de una U invertida (fig. $2 \mathrm{f}$ ). Cabe mencionar que el elemento de las dos bandas cruzadas también aparece como accesorio en otros motivos, como por ejemplo en composiciones asimétricas: una cruz cuyo extremo inferior izquierdo está unido a la última línea del motivo mano-pata-ala (fig. $2 \mathrm{~g}$ ).

Realizadas con la misma técnica de excavado, las cruces dispuestas en forma horizontal aparecen en la cerámica de Tlatilco y Zohapilco, ${ }^{20}$ Trapiche y 20. Christine Niederberger, Zohapilco, cinco milenios de ocupación humana en un sitio lacustre de 
Tabla 2. Presencia de la cruz en algunos monumentos pétreos

\begin{tabular}{lcl}
\hline Sitio & Monumento & Contexto \\
\hline San Lorenzo & 52 & En el pectoral del ser antropomorfo con cabeza hendida \\
San Lorenzo & 30 & En el ojo del dragón \\
San Lorenzo & 58 & En el torso de un pez \\
Loma del Zapote & I3 & Caja atada con cuerdas que forman una cruz \\
La Venta & Altar 4 & En las fauces de la máscara bucal del dragón \\
La Venta & Altar 5 & En la banda del tocado \\
La Venta & 30 & En el pectoral de una figura humana \\
La Venta & I9 & En la banda del tocado \\
Laguna de los Cerros & 9 & Formando la atadura de una caja \\
Laguna de los Cerros & I & En un ojo \\
Laguna de los Cerros & 2 & En un ojo \\
Chalcatzingo & 5 & En la espalda del dragón \\
Las Limas & Figura & En el pectoral y en el cinturón del niño \\
Izapa & Estela 2 & En la banda de las alas del ser que desciende \\
Izapa & Estela 4 & En la banda de las alas del ser que desciende \\
Izapa & Estela 22 & En la frente de un ser antropomorfo \\
Izapa & Estela 57 & En la frente de un ser antropomorfo \\
\hline
\end{tabular}

Chalahuite, ${ }^{21}$ y Chalcatzingo. ${ }^{22}$ En los monumentos de piedra no se presenta la cruz dispuesta en serie horizontal; más bien aparece en diferentes contextos. La tabla 2 ofrece un listado del contexto de la cruz en varios monumentos, algunos de los cuales se ilustran en la figura 6 .

\section{La U invertida dispuesta en serie horizontal}

$\mathrm{Al}$ igual que la cruz, el elemento en forma de $\mathrm{U}$ invertida se presenta repetido en la composición simétrica conformada por una secuencia a lo largo de una

la cuenca de México, México, Instituto Nacional de Antropología e Historia-Departamento de Prehistoria (Colección Científica, 30), 1976; Paléopaysages et Archéologie Pré-urbaine du Bassin de Mexico (Mexique), México, Centre d'Études Mexicaines et Centroaméricaines (Études Mésoaméricaines XI:I-II), I987, vol. II, pp. 515, 520.

2I. José García Payón, Prehistoria de Mesoamérica. Excavaciones en Trapiche y Chalahuite, Veracruz, México, 1942, I95I y 1959, México, Universidad Veracruzana (Cuadernos de la Facultad de Filosofía, Letras y Ciencias, 3I), I966, p. I70.

22. Román Piña Chan, Chalcatzingo, Morelos, México, Instituto Nacional de Antropología e Historia, 1955, pp. 58. 

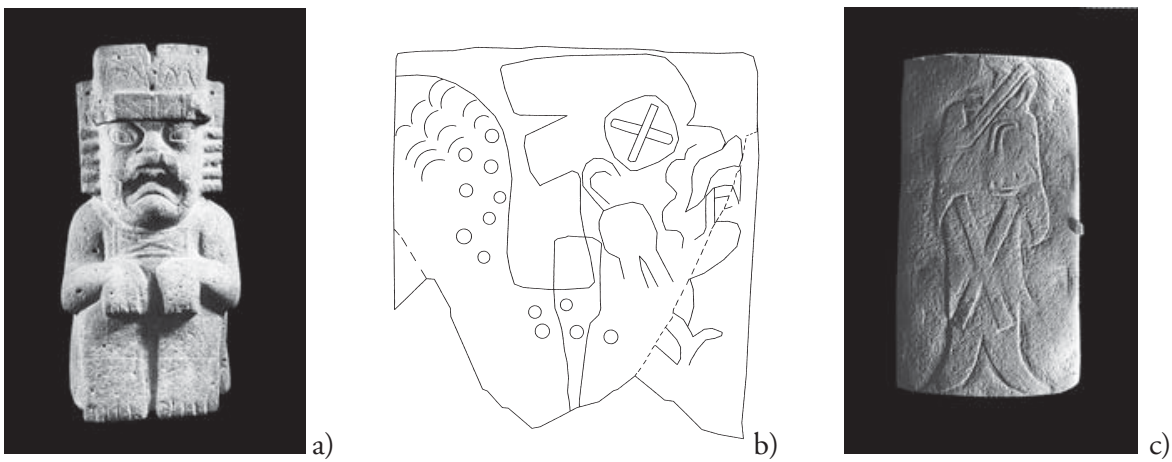

4. Monumentos de piedra que presentan cruces: a) el Monumento 52 de San Lorenzo, con la cruz en el pectoral; b) el Monumento 30 de San Lorenzo, con la cruz en el ojo, y c) el Monumento 58 de San Lorenzo, con la cruz sobre el cuerpo. Fotos: Brizio Martínez.

banda alrededor de la vasija (fig. 2c); a veces cada repetición está intercalada con líneas verticales u oblicuas (fig. 2d) o enmarcando una cruz (fig. 2f). Tal como se observa en numerosas vasijas completas, esta disposición en serie conforma uno de los motivos Calzadas más frecuentes en el sitio y su significado parece ser equivalente al del motivo conocido como "la doble línea interrumpida" que generalmente se encuentra sobre o cerca del borde de vasijas comunes en otras regiones. En San Lorenzo no es un diseño pequeño como los ejemplares foráneos en donde se limita al borde y más bien cubre la pared exterior de las vasijas.

Este motivo también fue usado como accesorio: por ejemplo, como elemento inferior de un ser zoomorfo-antropomorfo, del cual, aparentemente, constituye la encía. ${ }^{23}$ Esto se observa en varios monumentos pétreos, tal como se describe en la tabla 3 (véase también fig. 5). Varios estudiosos han notado en el simbolismo de este ser monstruoso significados terrenales y celestes (tabla 4).

De Zohapilco, Christine Niederberger ${ }^{24}$ muestra una vasija donde aparece este motivo en la misma disposición que en las vasijas de San Lorenzo, pero con otra técnica de manufactura, y otra pieza que combina la banda con el motivo en forma de U con la cruz de san Andrés. ${ }^{25}$ En el centro de México, la U invertida aparece, de la misma manera que en San Lorenzo, como elemento de la encía de seres zoomorfos con ceja flamígera, al igual que lo muestra la figurilla

23. Peter D. Joralemon, A Study of Olmec Iconography. Studies in Pre-Columbian Art and Archaeology, Washington, Dumbarton Oaks, núm. 7, I97I.

24. Niederberger, Paléopaysages et Archéologie..., op. cit., vol. II, p. 543.

25. Ibidem, p. 520. 
Tabla 3. Presencia de la U invertida en varios monumentos pétreos de la costa del Golfo

\begin{tabular}{lcl}
\hline Sitio & Monumento & Contexto \\
\hline Loma del Zapote & 2 & En la orilla del cuerpo superior del trono \\
Estero Rabón & 8 & En la orilla del cuerpo superior del trono \\
La Venta & Altar 4 & En la orilla del cuerpo superior del trono \\
\hline
\end{tabular}

en terracota conocida como el Sacerdote de Atlihuayán. El motivo en forma de $\mathrm{U}$ invertida que constituye una banda no ha sido reportado en la literatura sobre Oaxaca. Sin embargo, hay que destacar que son múltiples los ejemplos de la doble línea interrumpida en las vasijas de esta región, motivo que, como apuntan Kent V. Flannery ${ }^{26}$ y Ann Cyphers, ${ }^{27}$ es muy semejante.

\section{Mano-ala-pata de composición simétrica}

Los ejemplares más completos muestran un conjunto de tres líneas rectas paralelas que divergen, o sea, se unen transversalmente a otras tres; marcando la coyuntura se encuentra un pequeño trazo, a manera de espolón (figs. Ia-2g). La composición alrededor de la vasija está compuesta por series de este elemento —colocados siguiendo un patrón simétrico de reflexión- separadas por tres líneas verticales, dos de ellas con elementos en forma de $\mathrm{L}$ o de $\mathrm{U}$, que dan la apariencia de una letra K. Una de las razones por las que se llama motivo manoala-pata es precisamente su indefinición, ya que podría ser la extremidad de un ser humano, un ave o un animal. Encontramos este motivo asociado con aves en objetos portátiles. ${ }^{28}$

En la literatura sobre Oaxaca no se ha reportado este motivo. En el Altiplano se identificaron muchos fragmentos que pudieron haber sido parte de esta composición. Un ejemplar que presenta un patrón similar muestra tres líneas horizontales paralelas dispuestas de manera decreciente, unidas transversalmente a tres líneas verticales, aunque sin el espolón, sin mediar ninguna línea de sepa-

26. Apud Stephen Plog, "Measurement of Prehistoric Interaction between Communities", en Kent V. Flannery (comp.), The Early Mesoamerican Village, Nueva York, Academic Press, 1976.

27. Ann Cyphers, La escultura olmeca de San Lorenzo Tenochtitlán, México, Universidad Nacional Autónoma de México-Coordinación de Humanidades-Instituto de Investigaciones Antropológicas, 2004, p. 235.

28. Joralemon, "The Olmec Dragon...", op. cit., fig. 5 b. 

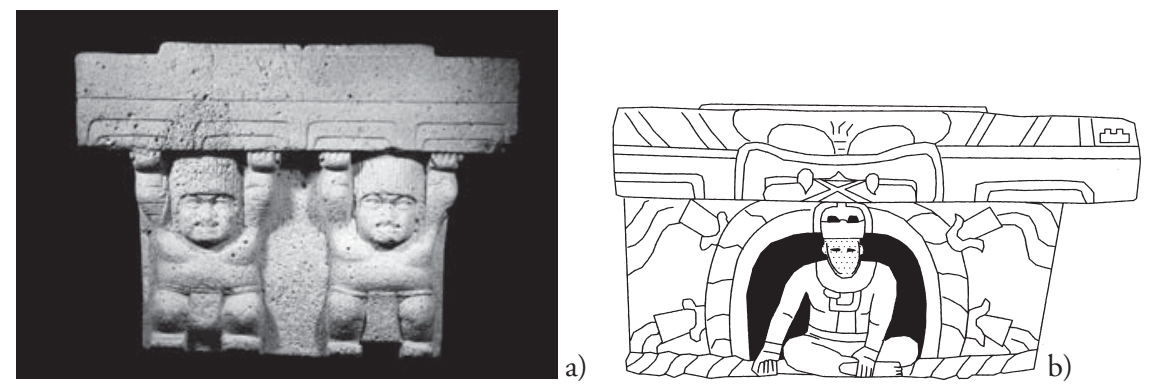

5. Dos tronos con la representación pars pro toto (serie de Úes invertidas) del monstruo cósmico en el lado frontal del cuerpo superior: a) el Monumento 2 de Loma del Zapote. Tomado de Ann Cyphers, La escultura olmeca de San Lorenzo Tenochtitlán, México, Universidad Nacional Autónoma de México-Coordinación de Humanidades-Instituto de Investigaciones Antropológicas, 2004, p. 236; b) el Altar 4 de La Venta. Dibujo de Ann Cyphers.

ración entre la repetición de este motivo a lo ancho de la vasija, y sin mostrar repeticiones conforme a una simetría por reflexión.

Por analogía con culturas posteriores, se puede observar que este motivo podría tener varios significados de acuerdo con el contexto en que se encuentra (tabla 5). Es particularmente interesante la propuesta de Karl Taube, ${ }^{29}$ según la cual significaría el viento, así como su asociación con aves. Algunos monumentos pétreos de la costa del Golfo muestran la inclusión de este motivo en su composición. Destaca la presencia de una pata de ave en el tocado de varios personajes (tabla 6 y fig. 6).

\section{El dragón de composición asimétrica}

En San Lorenzo, la principal característica de este motivo es la cabeza de perfil de un ser, algunas veces llamado dragón, que consta de dos partes: en la superior se encuentra una gran ceja flamígera, un ojo (a veces en forma de U) y una nariz (en ocasiones humana), y debajo un trapecio que contiene dos Úes invertidas o una fila de dientes. El motivo mano-ala-pata siempre se encuentra del lado izquierdo de la cabeza (figs. Id y 3 ).

29. Karl Taube, "The Rainmakers: The Olmec and their Contributions to Mesoamerican Belief and Ritual”, en Michael D. Coe, The Olmec World, Ritual and Rulership, Princeton, Princeton University/The Art Museum, 1995, p. 85. 
ICONOGRAFÍA DE LA CERÁMICA DE SAN LORENZO

Tabla 4. Interpretación de la U invertida según varios autores

\begin{tabular}{ll}
\hline Interpretación & Autor \\
\hline Ojo del jaguar & Clewlow 1974: 77; Stirling 1965: 730 \\
Luna & Coe I965: 759-76I \\
Monstruo de la Tierra & De la Fuente 1984: I52 \\
Maxilar del jaguar & Drucker 1952: 200-206 \\
Encías sin dientes del monstruo terrenal & Reilly I994: 244 \\
Icono de la lluvia & Niederberger 1987: II: 543 \\
Hocico de jaguar & Norman 1976: 45-46 \\
Confiere rasgos felinos a criaturas compuestas & Quirarte 1977: 264 \\
\hline
\end{tabular}

En San Lorenzo, una característica de la mano-ala-pata, como parte de este motivo, es la presencia de tres o más líneas rectas paralelas que a cierta distancia se desvían hacia abajo o hacia arriba, conformando lo que podría ser una mano, un ala o una pata esquematizada, asociada a los otros elementos que configuran al ser antropo-zoomorfo. En el Altiplano son múltiples los motivos similares (fig. Id), aunque allí algunos son más figurativos, ya que muestran patas con garras. En esta región también existen composiciones simétricas que combinan algunos elementos del ser zoomorfo-antromorfo, como la ceja y la encía. ${ }^{30}$ Significativamente, en la bibliografía sobre Oaxaca no ha sido reportado ninguno de ellos.

La ceja escalonada o flamígera es uno de sus atributos más frecuentes. Román Piña Chan ${ }^{31}$ considera la ceja escalonada un rasgo del jaguar, el cual "representa las montañas o los cerros"; pero, cuando adopta la forma de ceja flamígera, el mismo autor la interpreta como "flama o fuego" asociada con la serpiente. Cuando este elemento presenta líneas paralelas, lo traduce como "lluvia sobre las montañas". ${ }^{32}$ Para Donald W. Lathrap, ${ }^{33}$ la ceja flamígera puede representar la cresta del águila arpía, un símbolo del Sol.

30. Muriel Porter Weaver, Tlapacoya Pottery in the Museum Collection. Indian Notes and Monographs, Nueva York, Heye Foundation-Museum of the American Indian, núm. 56, 1967, lám. o.

3I. Román Piña Chan, El lenguaje de las piedras. Glifica olmeca y zapoteca, México, Fondo de Cultura Económica, 2002, p. 3 I.

32. Ibidem, p. 3 I.

33. Donald W. Lathrap, "Complex Iconographic Features Shared by Olmec and Chavin and Some Speculations as to their Possible Significance", ponencia presentada en el Primer Simposio de Correlaciones Antropológicas Andino-Mesoamericanas, Ecuador, I97I. 
Tabla 5. Interpretaciones de la mano-ala-pata por varios autores

\begin{tabular}{ll}
\hline Interpretación & Autor \\
\hline El significado en la escritura maya varía & \\
de acuerdo con el sufijo y el afijo & Boot 2004 \\
Símbolo del poder (dar y quitar vida) & Piña Chan 2002: 3I \\
Representa el lenguaje gestual de la elite maya & Boot 2004 \\
Pata del gran cocodrilo & Flannery y Marcus 2000: I3 \\
Felino & Joralemon I97I: 35 \\
Mano amputada & Ladrón de Guevara 2005; Piña Chan 1972: I2, I4 \\
Pata de caimán & Muse y Stocker 1974: 8I \\
Viento & Taube 1995: 85 \\
\hline
\end{tabular}

El mascarón de la Estructura 34 de El Mirador, Guatemala, llamada también Templo de la Garra del Jaguar, muestra mucha semejanza con el motivo manoala-pata unido a la cabeza de un ser zoomorfo-antropomorfo, pero en una vista frontal; sin embargo, esta representación es muy posterior, ya que está fechada en el Preclásico tardío. 34

En diversos monumentos y un mural (tabla 7), el dragón tiene connotaciones terrestres, tal como han señalado varios autores (tabla 8).

\section{Observaciones sobre el significado general}

Indican varios estudios que un temprano modelo olmeca del universo se centra en un monstruo cósmico que encarna aspectos celestes y terrestres a través de la integración de rasgos de felino, serpiente y ave..$^{35}$ Estos estudios iconográficos,

34. Richard D. Hansen, "El Mirador, Guatemala. El apogeo del Preclásico en el área maya", Arqueología Mexicana, México, vol. XI, núm. 66, 2004, p. 3I.

35. David C. Grove, "Faces of the Earth at Chalcatzingo: Serpents, Caves, and Mountains in Middle Formative Period Iconography”, en John Clark y Mary Pye (comps.), Olmec Art and Archaeology in Mesoamerica, Washington, National Gallery of Art, 2000, pp. 277-295; Kent Reilly III, "Art, Ritual and Rulership in the Olmec World", en Michael D. Coe, The Olmec World..., op. cit., pp. 27-45; Taube, op. cit.; Marcus, op. cit.; Jacinto Quirarte, "Early Art Styles of Mesoamerica and Early Classic Maya Art", en Richard E.W. Adams (comp.), The Origins of Maya Civilization, Albuquerque, University of New Mexico Press, 1977, pp. 249-283; W. Garth Norman, "Izapa Sculpture", part 2: Text. Papers of the New World Archaeological Foundation, Provo, Utah, Brigham Young University/New World Archaeological Foundation, núm. 30, 1976; 
Tabla 6. Presencia de la mano-ala-pata en monumentos pétreos

\begin{tabular}{|c|c|c|}
\hline Sitio & Monumento & Contexto \\
\hline San Lorenzo & Monumento 5 & $\begin{array}{l}\text { hsignia de dos patas de ave en el tocado de la cabeza } \\
\text { colosal }\end{array}$ \\
\hline San Lorenzo & Monumento 89 & $\begin{array}{l}\text { hsignia de una pata de ave en el tocado de la cabeza } \\
\text { colosal }\end{array}$ \\
\hline San Lorenzo & Monumento 53 & Insignia de manos en el tocado de la cabeza colosal \\
\hline San Lorenzo & Monumento I4 & En el tocado del personaje en una cara lateral del trono \\
\hline San Lorenzo & Monumento I06 & Tes patas de ave grabadas en un recubrimiento de escalón \\
\hline La Venta & Altar I & Mano-ala-pata en las caras laterales \\
\hline La Venta & Monumento 4 & Insignia en el tocado de la cabeza colosal \\
\hline Loma del Zapote & Monumento 3 & Dos manos en la parte posterior de la escultura múltiple \\
\hline Loma del Zapote & Monumento I2 & Mano-ala-pata en la banda que circunda la cabeza humana \\
\hline Chalcatzingo & Monumento IO & $\begin{array}{l}\text { In la cima del cerro Chalcatzingo junto al bajorrelieve } \\
\text { de una cabeza humana con casco cónico }\end{array}$ \\
\hline $\begin{array}{l}\text { Laguna de } \\
\text { los Cerros }\end{array}$ & Monumento I3 & En el lado de una figura antropozoomorfa \\
\hline
\end{tabular}

aunque muestran diferencias en la interpretación de particularidades, sugieren que esta criatura era la fuente de la fertilidad, del éxito agrícola y del poder de los gobernantes. Los múltiples aspectos del monstruo integran nociones sagradas de la Tierra y el Cielo.

Los elementos que hemos presentado en este trabajo, las bandas cruzadas, la $\mathrm{U}$ invertida y la mano-ala-pata, se encuentran en las representaciones frontal y lateral ${ }^{36}$ del monstruo, al igual que otros como los colmillos y la ceja flamígera. De acuerdo con las analogías arriba mencionadas, el significado de los elementos puede aproximarse.

El elemento de las bandas cruzadas tiene connotaciones celestes, principalmente el Sol, ${ }^{37}$ mientras que la $\mathrm{U}$ invertida hace referencia a la boca del mons-

Joralemon, A Study..., op. cit.; Román Piña Chan, Quetzalcóatl, Serpiente Emplumada, México, Fondo de Cultura Económica, 1977; Los olmecas: La cultura madre, Barcelona, Lunwerg, 1990; Angulo, op. cit.; Jorge Angulo, "Observaciones sobre su pensamiento cosmogónico y la organización sociopolítica”, en John Clark (comp.), Los olmecas en Mesoamérica, México, Citibank/El Equilibrista, 1994, pp. 223-238.

36. Kent Reilly III, op. cit., p. 36; Grove, "Faces of the Earth...", op. cit., p. 283.

37. Norman, op. cit., p. 33; Piña Chan, El lenguaje de las piedras..., op. cit., p. 29; Román Piña Chan y Luis Covarrubias, El pueblo del jaguar (Los olmecas arqueológicos), México, Consejo para la Planeación e Instalación del Museo Nacional de Antropología, 1964, p. 46. 
a)
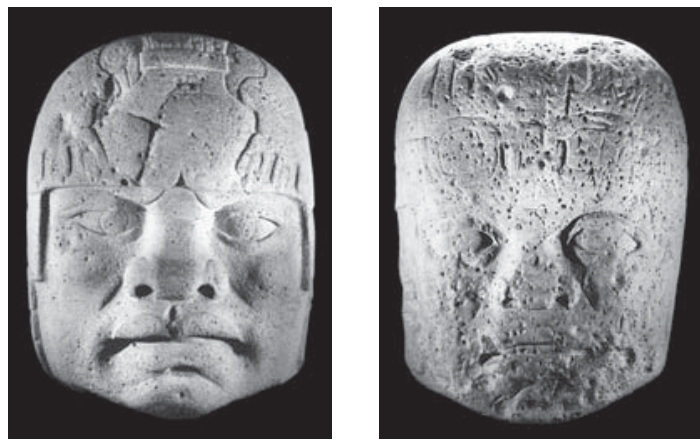

b)

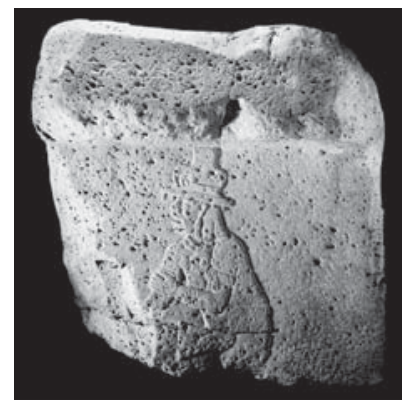

c)
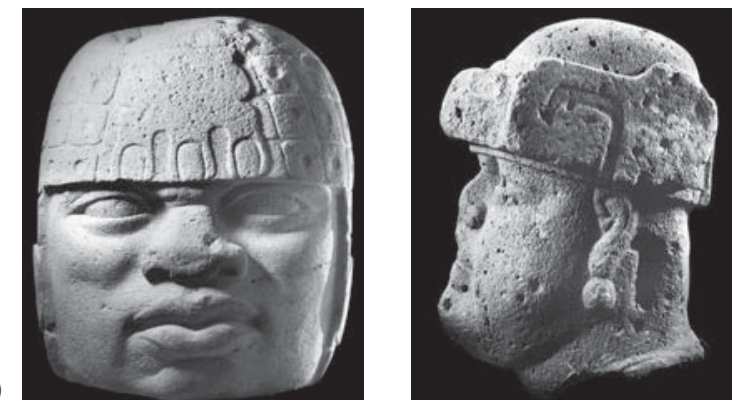

e)

6. Monumentos de piedra que muestran una versión del elemento mano-ala-pata:

a) Monumento 5 de San Lorenzo, cabeza colosal con dos patas de ave encima del casco;

b) Monumento 53 de San Lorenzo, cabeza colosal con dos manos encima del casco; c) cara derecha del trono, Monumento I4 de San Lorenzo, que muestra una pata de ave en el tocado del personaje sedente; d) Monumento 89 de San Lorenzo, cabeza colosal con una pata de ave que adorna el casco; e) Monumento I2 de Loma del Zapote, cabeza de una gran figura de bulto que presenta el elemento mano-ala-pata en la banda que circunda la cabeza. Tomados de Ann Cyphers, La escultura olmeca de San Lorenzo Tenochtitlán, México, Universidad Nacional Autónoma de México-Coordinación de Humanidades-Instituto de Investigaciones Antropológicas, 2004, p. 259. Fotos: Brizio Martínez. 
Tabla 7. Representaciones diversas del dragón en monumentos pétreos y pintura mural

\begin{tabular}{ll}
\hline Sitio & Monumento \\
\hline Loma del Zapote & Monumento 2 \\
Estero Rabón & Monumento 8 \\
La Venta & Estela I \\
La Venta & Altar I \\
La Venta & Altar 4 \\
Oxtotitlán & Mural I \\
El Mirador & Mascarón de la Estructura 34 \\
Chalcatzingo & Monumentos I, 5, 9 y 22 \\
\hline
\end{tabular}

truo, la cual cuenta con significados celestes y terrestres. ${ }^{38}$ La mano-ala-pata puede referirse al viento. ${ }^{39} \mathrm{~A}$ partir de estos significados principales de Cielo y Tierra, el monstruo parece ser un símbolo integral del universo olmeca.

\section{Zohapilco}

El dragón-monstruo se encuentra explícitamente representado en varios monumentos pétreos, al igual que en las vasijas cerámicas, estas últimas propuestas como el medio utilizado para la transmisión interregional de las creencias cosmológicas olmecas. ${ }^{40}$ En contraposición, se cuestiona su origen olmeca ${ }^{4 \mathrm{I}}$ y se ha planteado que el sitio de Zohapilco, en la cuenca de México, tiene evidencia que le confiere primacía temporal en cuanto a la cerámica portadora de estos elementos y motivos, fechada desde I350 a.C. $4^{42}$

No obstante, hay problemas de interpretación estratigráfica en la secuencia de Zohapilco que repercuten en la temporalidad de los depósitos culturales y,

38. Norman, op. cit.; Taube, op. cit; Joralemon, A Study..., op. cit.; Javier Urcid, "Knowledge, Power, and Memory in Ancient Oaxaca", publicado en www.famsi.org/zapotecwriting/zapotec_text.pdf, 2005; Quirarte, op. cit;; Reilly III, op. cit.; Grove, "Faces of the Earth...", op. cit.

39. Taube, op. cit.

40. John E. Clark, "The Arts of Government in Early Mesoamerica”, Annual Review of Anthropology, núm. 26, 1977, pp. 2II-234; Jeffrey P. Blomster et al., op. cit.

4I. Marcus, op. cit.; Demarest, op. cit.; Flannery et al., op. cit.; B. Stoltman et al., op. cit.; Grove, "Olmec...", op. cit.

42. Flannery y Marcus, op. cit. 
Tabla 8. Interpretación del dragón por varios autores

\begin{tabular}{ll}
\hline Interpretación & Autor \\
\hline Cocodrilos, Tierra & Muse y Stocker 1974: 8I; Angulo 1994: 232, 234; Reilly 1994 \\
Felino & Joralemon 197I: 35-4I \\
Cielo, relámpago & Marcus 1989; Flannery y Marcus 2000: 216 \\
\hline
\end{tabular}

por ende, en la de las cerámicas decoradas en cuestión. Las fases pertinentes son la Nevada (I35O-I250 a.C.) y la Ayotla (I250-IO00 a.C.), las cuales se definen a partir de estratos excavados en la trinchera de $50 \mathrm{~m}$ de largo que cruzó el sitio. ${ }^{43}$ Niederberger define la fase Nevada a partir de los estratos inferiores, I2 y I3, mientras que asigna los estratos superiores, 9 y IO-II, a la fase Ayotla (fig. 7). Hay dos fechas de radiocarbono que son pertinentes en la siguiente discusión: la muestra RC-4 arroja una temporalidad de $1360+/$ - IIO a.C. y deriva del estrato I3 de la sección Aio, su contexto corresponde a la fase Nevada; la muestra RC-2, procedente del estrato $8 \mathrm{~b}$ de la sección A25, fecha al IO4O +/- IOO a.C. y corresponde a la fase Manantial (Iooo-800 a.C.). ${ }^{44}$

El corte estratigráfico muestra que el estrato i3 es continuo a lo largo de la trinchera mientras que los estratos 9, IO, II y I2 se localizan en las secciones que van del A-I9 al A-30. Los estratos 9, IO, II y I2 son inclinados y parecen representar una deposición secundaria porque los estratos 9 y I2 se componen del mismo suelo, el cual contiene dos lentículas en su interior, marcadas como estratos Io y II. Cabe hacer hincapié en el hecho de que no hay una diferenciación en cuanto a la simbología de los suelos mostrados en el corte para los estratos $9 \mathrm{y}$ I2; igualmente, la descripción de los suelos en el texto es muy semejante, lo que coincide con lo observable en las fotografías de la pared. ${ }^{45}$ Además, Niederberger menciona que el estrato io es redepositado. ${ }^{46}$ Consecuentemente, lo que se define como estratos 9 y I2 constituye, en realidad, una sola unidad edafológica y deposicional dentro de la cual se ubican los estratos io y II.

Esto señala que los estratos 9-I2 deberían interpretarse como un solo evento de deposición a lo largo del área excavada. Además, el estrato I2 de la fase Nevada

43. Christine Niederberger, "Zohapilco, cinco milenios de ocupación humana en un sitio lacustre de la cuenca de México”, tesis de licenciatura, México, Escuela Nacional de Antropología e Historia, 1974.

44. Ibidem, p. 4I.

45. Ibidem, pp. 39, 4I y foto 9.

46. Ibidem, p. 59. 


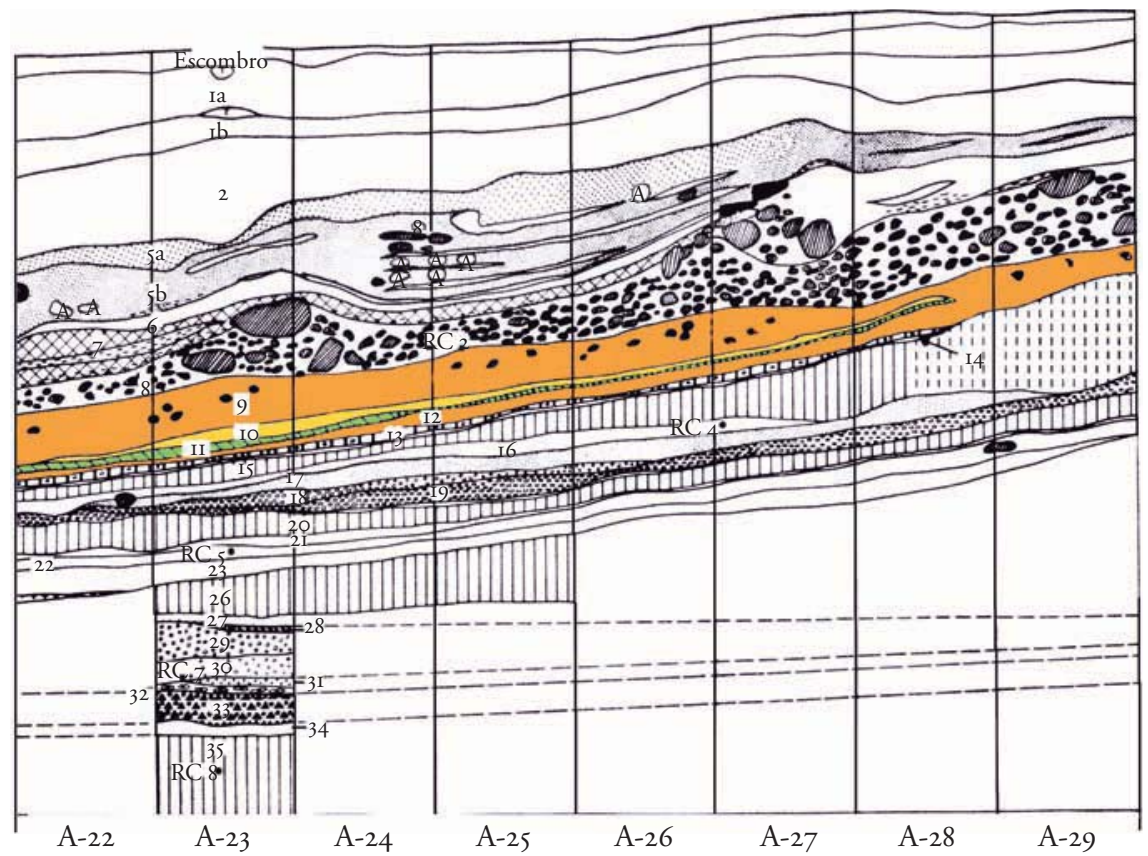

7. Corte estratigráfico de las secciones A22-A29 de la trinchera excavada en Zohapilco. Dibujo de Ann Cyphers, versión modificada de la de Christine Niederberger, Zohapilco, cinco milenios de ocupación humana en un sitio lacustre de la cuenca de México, México, Instituto Nacional de Antropología e Historia-Departamento de Prehistoria (Colección Científica, 30), 1976, lám. IV. Los estratos 9, IO, II y I2 representan una sola unidad de deposición.

definida por Niederberger no es temporalmente distinto a los estratos de su fase Ayotla (i.e. 9, Io y II). Igualmente, en el reporte de los motivos cerámicos se registra únicamente la distribución por fase, no por estrato. No se proporcionan los datos de cada sección de la trinchera de manera independiente, y sólo se ofrecen en términos de la globalidad del estrato. En consecuencia, las frecuencias de los tipos cerámicos de los estratos de bajo escrutinio deben sumarse dentro de una sola unidad temporal debido al carácter inclusivo del suelo que componen los estratos 9 y I2. La anterior consideración de los procesos de deposición afecta de manera dramática la secuencia de Zohapilco. Nevada sigue siendo una fase discreta con base en el contenido del estrato 13. No obstante, los suelos que corresponden a la fase Ayotla deben redefinirse como los estratos 9, IO, il y I2. 

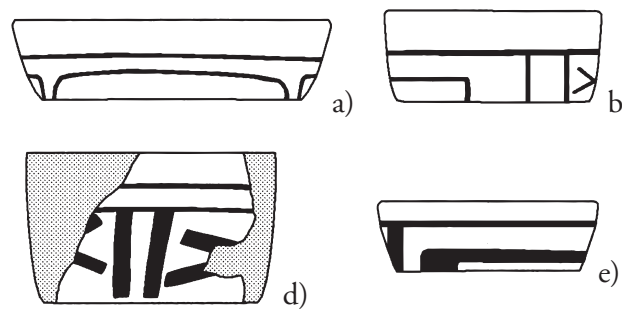

d)

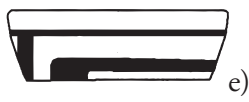

e)

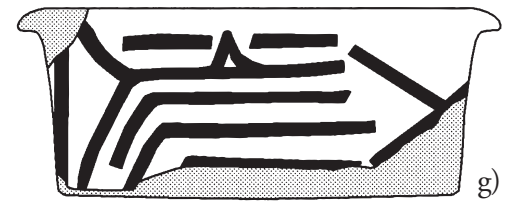

g) b)
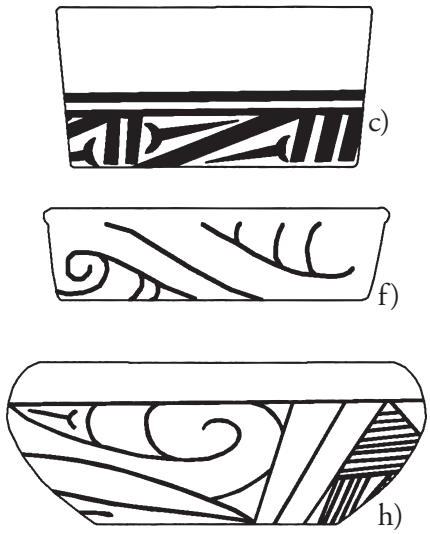

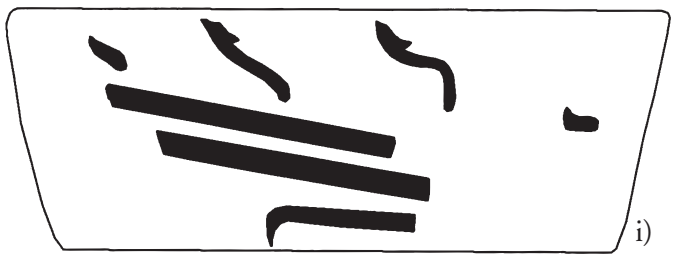

Simbología:

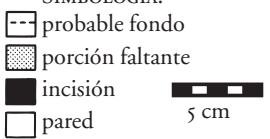

8. Cerámica de las fases San Lorenzo A y B que muestra el simbolismo de Tierra y Cielo: a-b), d-e) serie horizontal de Úes invertidas y cruces; c) serie horizontal de elementos en forma de espina enmarcados por líneas horizontales y verticales; f, h) volutas en forma de $\mathrm{S}$ acostada, elemento en forma de espina y achurado cruzado; g) mano-ala-pata y cruz; i) representación pars pro toto. Dibujos de Ann Cyphers.

Es importante destacar que Flannery y Joyce Marcus 47 manipulan los datos de la cerámica de Zohapilco con el fin de validar la primacía de los motivos del Complejo X fuera de la costa del Golfo. Primeramente, se concentran en los tipos cerámicos en lugar de la frecuencia de los motivos y los motivos mismos, ${ }^{48}$ lo que hace parecer que ciertos motivos del Complejo X se encuentran en cada tiesto de los tipos Tortuga Pulido, Volcán Pulido, Atoyac Gris Fino, Valle Borde Blanco, Pilli Blanco y Paloma Negativo. Ello no es correcto, pues en los estratos Nevada, I2 y I3, hay 35 tiestos con achurado zonificado o incisión de línea fina, ${ }^{49}$

47. Flannery y Marcus, op. cit.

48. Ibidem, p. I9.

49. Todos los cuales se registran en Niederberger, Zohapilco, cinco milenios..., op. cit. 

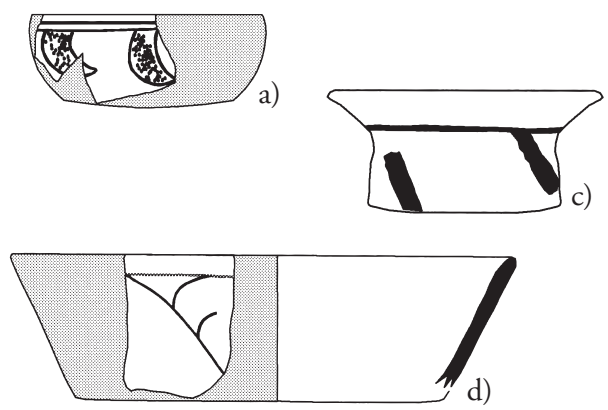

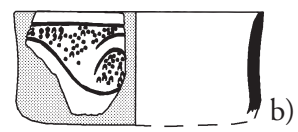

Simbología:

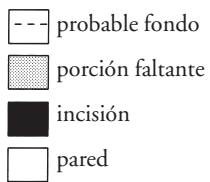

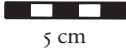

9. Cerámica de la fase Bajío que muestra el simbolismo de Tierra y Cielo: a) elementos en forma de colmillo con punzonadas zonificadas; b) voluta en forma de $S$ parcial con punzonadas zonificadas; c) manifestación temprana de la incisión ancha; d) representación estilizada de la voluta. Dibujos de Ann Cyphers.

lo que constituye menos de 5 por ciento de los tiestos de los tipos relacionados o I.Is por ciento del total de tiestos por dicha fase. La afirmación de que, "The dark grey wares on which they occurred had been among the most common local types at I350 b.C., and the motifs themselves were common by I250 b.C.", so distorsiona los datos, ya que Niederberger misma reporta que "En los niveles Nevada [...] las decoraciones típicas son las fajas de líneas paralelas finas, las líneas oblicuas entrecruzadas y el punzonado" ${ }^{5 \mathrm{I}}$ Lo anterior significa que en los estratos I2 y I3 no hay motivos del Complejo X. Por lo tanto, la frecuencia de tipos enfatizada por Flannery y Marcus no tiene ninguna relación con los tipos de motivos y su frecuencia.

Además de los problemas deposicionales no resueltos en la larga trinchera excavada en Zohapilco que repercuten en la interpretación de los estratos Nevada (I350-I250 a.C.) y Ayotla (I250-I000 a.C.), así como en la aparición de las cerámicas decoradas que aquí se consideran, cabe destacar que ningún otro sitio del Altiplano Central cuenta con una columna que corrobore la porción más temprana de esta secuencia. En el mismo sentido, es notable que los complejos cerámicos de estas fases diverjan de lo observado en otros sitios. Se pueden ilustrar algunos problemas en cuanto a marcadores temporales de horizonte que son inconsistentes, como los cajetes pseudomolcajete en la fase Ayotla,

50. Flannery y Marcus, op. cit., p. 2I.

5I. Niederberger, Zohapilco, cinco milenios..., op. cit., p. пा6. 
el achurado cruzado en cajetes de borde directo y la abundancia de motivos del tipo doble-línea-interrumpida en las fases Nevada y Ayotla.

Según tales observaciones, las fases tempranas de la secuencia cronológica de Zohapilco deben ser tratadas con reserva. Los procesos de formación (la deposición secundaria) que se observa en la columna estratigráfica del sitio arrojan dudas sobre la antigüedad de los motivos del Complejo X en los estratos 9-I2. Consideramos no recomendable señalarlo como el punto de origen de los motivos del Complejo X.

\section{Antigüedad de los conceptos Cielo y Tierra en San Lorenzo}

En San Lorenzo las vasijas que exhiben versiones del monstruo cósmico hechas con incisión ancha (fig. 3) son un marcador temporal de la fase San Lorenzo B, I000-850 a.C., ${ }^{52}$ mientras que las versiones pars pro toto (fig. 8i) aparecen desde la fase San Lorenzo A, II5O-I000 a.C., y llegan a su frecuencia máxima en la B. Los motivos plasmados con incisión ancha caracterizan ambas fases, la A y la B; ${ }^{53}$ no obstante, en la fase San Lorenzo A los motivos comunes son la cruz en serie horizontal, la $\mathrm{U}$ invertida en serie horizontal y la mano-ala-pata (figs. 8a, b, d, e y g).

Por otro lado, es importante destacar que el simbolismo de Tierra y Cielo en la cerámica de San Lorenzo aparece desde la fase Bajío, I350-I250 a.C. (fig. 9), mucho antes de su aparición en el arte pétreo y en las vasijas con decoración Calzadas. En la fase Bajío existe una decoración de línea fina donde predominan las volutas en forma de $S$ acostada y elementos con forma de colmillo (fig. 8; véase también Limón Carved Incised definido por Coe y Diehl). ${ }^{54}$ En la fase subsiguiente, las Chicharras, I250-II5O a.C., la incisión fina de volutas en forma de $S$ acostada y Us invertidas (fig. Io) inicia su ascenso de popularidad, que continúa a lo largo de las fases San Lorenzo A y B, II50-850 a.C. A lo largo de estas fases, las volutas $S$ acostadas se asocian con un elemento tejido y otro con forma de espina (figs. 8c y h).

Se ha considerado que la voluta en forma de $S$ acostada en las vasijas de $S a n$ Lorenzo es el ilhuitl, 55 aunque es más probable que sea el símbolo del cielo,

52. Cyphers, "La cerámica de San Lorenzo...", op. cit.

53. Véase también Coe y Diehl, op. cit., vol. I, pp. I62-174.

54. Ibidem, vol. I, pp. I7I-I74.

55. Idem, p. I7I. 

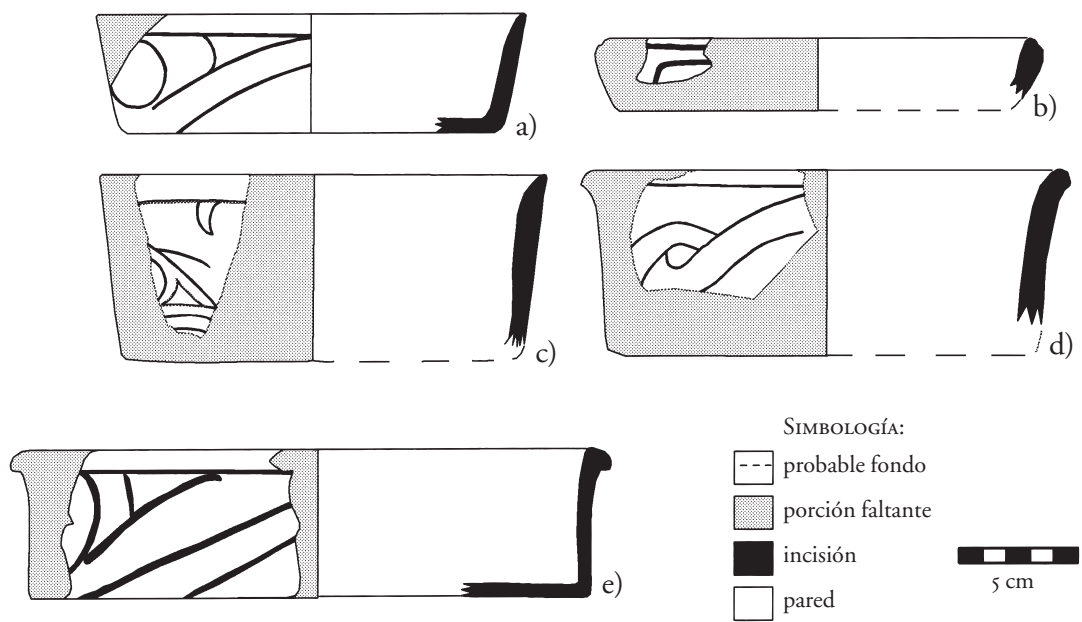

Io. Cerámica de la fase Chicharras que muestra el simbolismo de Tierra y Cielo: a, d, e) versiones de la voluta en forma de $S$; b) elemento de $U$ invertida; c) elemento en forma de espina y voluta estilizada. Dibujos de Ann Cyphers.

ilhuicatl..$^{5}$ En los jeroglíficos mayas tiene el significado de nube. ${ }^{57} \mathrm{El}$ significado del elemento tejido, a través de comparaciones con los jeroglíficos mayas, puede referirse a la Tierra. ${ }^{58} \mathrm{El}$ elemento en forma de espina tiene la forma de una línea incisa oblicua que termina con un pequeño arco inciso; consideramos la posibilidad de que este elemento haga referencia a un implemento para el autosacrificio; no obstante, su colocación cerca de la voluta en forma de $S$ acostada sugiere que puede ser un símbolo de viento o relámpago.

$\mathrm{Al}$ respecto de este motivo, se ha planteado que representa el soplo divino, $i k .59$ Se ha interpretado su presencia en el flanco izquierdo de un felino (Monumento 7 de San Lorenzo) como prueba de que en esta región se creó este símbolo. ${ }^{60}$ Vinculado con ámbitos celestes, en Chalcatzingo sustituye al

56. Stephen Houston y Karl Taube, "An Archaeology of the Senses: Perception and Cultural Expression in Ancient Mesoamerica”, Cambridge Archaeological Journal, vol. Io, núm. 2, 2000, pp. 26I-294.

57. Taube, op. cit., p. 96.

58. Véanse, por ejemplo, glifos T526, T526:136, T526:88 y T526:246 en John Montgomery, Dictionary of Maya Hieroglyphs, www.famsi.org/mayawriting/dictionary/montgomery/, 2002.

59. Angulo, "Observaciones sobre...", op. cit., p. 235.

6o. Kent Reilly III, "Cosmología, soberanismo y espacio ritual en la Mesoamérica del Formativo”, en Clark (comp.), op. cit., p. 246. 
motivo de nube y está relacionado con un complejo simbólico asociado con el sacrificio y la fertilidad, debido al vínculo entre nube, humo y serpiente de las visiones. ${ }^{61}$ Stephen Houston y Taube ${ }^{62}$ proponen que el uso de este diseño indica la emanación de un estímulo que es percibido a través de los sentidos de manera sinestésica. Según el contexto, el ilhuitlindicaría olor, aliento, emanación, sonido y reflexión de la luz, todas ellas manifestaciones etéreas e inasibles.

Miguel Covarrubias ${ }^{63}$ afirma que se encuentra,

desde tiempos muy remotos, una especie de dragón cuyo cuerpo está formado de volutas, probablemente nubes, sobre una estela encontrada en Tres Zapotes [...] Este concepto quizá evolucionó hasta la serpiente emplumada y la bicéfala, y puede reconocerse en la barra ceremonial que sostienen en sus brazos los sacerdotes mayas, o en los extraños objetos en forma de U de la costa del Golfo, conocidos con el nombre de "yugos de piedra".

Por lo anterior, las vasijas adornadas con la voluta en forma de $S$ acostada y sus elementos accesorios como el colmillo y el tejido están cargadas con mensajes sobre la Tierra y el Cielo, de modo similar al del monstruo cósmico o dragón. La continuidad temporal en los conceptos mencionados muestra que diferentes formas pueden tener el mismo significado a lo largo del tiempo. El encadenamiento de los conceptos de Cielo y Tierra en diferentes formas y tipos cerámicos da inicio alrededor de 1350 a.C.

Hasta la fecha, los datos disponibles indican su mayor antigüedad en San Lorenzo, la cual no tiene paralelo hasta ahora en ningún otro sitio. Antes de II5O a.C., no se observan volutas en las cerámicas tempranas de Puebla, Morelos y Oaxaca, ${ }^{64}$ lo cual sugiere que estas regiones no compartieron una temprana ideología donde figure este motivo y sus conceptos asociados. ${ }^{65}$ En la costa del Pacífico, grandes espirales sencillas adornan los tecomates desde la fase Barra

6I. Ibidem, pp. 246, 248 y 249.

62. Houston y Taube, op. cit.

63. Covarrubias, op. cit., p. 69.

64. Véase Richard S. MacNeish et al., The Prehistory of the Tehuacán Valley, Ceramics, Austin, University of Texas Press, 1970, vol. 3; Ann Cyphers, "Ceramics", en David C. Grove (comp.), Ancient Chalcatzingo, op. cit., 1987, pp. 200-251; Kent V. Flannery y Joyce Marcus, Early Formative Pottery of the Valley of Oaxaca, Mexico, Memoirs of the Museum of Anthropology, Ann Arbor, University of Michigan, núm. 27, 1994.

65. Véase también Richard Lesure, "Animal Imagery, Cultural Unities, and Ideologies of Inequality in Early Formative Mesoamerica”, en Clark y Pye (comps.), op. cit., pp. 193-215. 
(I550-I400 a.C.), ${ }^{66}$ y no se asemejan a la $S$ acostada. No obstante, este antecedente de la espiral es significativo por su asociación con vasijas que pudieron servir para almacenar granos y líquidos, ${ }^{67}$ entre ellos agua.

Lo anterior indicaría que estos conceptos surgieron en San Lorenzo, pues resulta claro que ahí por primera vez se plasmaron en un medio tangible. La palpable aparición de estos conceptos sagrados debe señalar su invención y cristalización material para ciertos fines internos de la sociedad de San Lorenzo.

\section{Observaciones}

El estudio de la función de las cerámicas decoradas en las fases tempranas, Bajío y Chicharras, se dificulta por la muestra limitada que se ha obtenido de estas ocupaciones profundamente enterradas en San Lorenzo. No obstante, a partir de la fase San Lorenzo A, parece que uno de sus propósitos era propagar las nociones estructurales del cosmos en una amplia población y de esta manera regular el pensamiento en todos los niveles.

Conjuntamente con el incremento de las cerámicas decoradas aparecen los motivos relacionados con Tierra y Cielo en el arte monumental. Este medio, no accesible a todos los sectores sociales, elevaba los conceptos a un plano mayor en donde la estrecha conexión cosmológica servía para certificar la posición social de la elite. Su asociación con los tronos fue privilegio de los gobernantes y respaldaba los conceptos de origen divino, ancestros sagrados y legitimación del jerarca. En monumentos de menor tamaño, los elementos sagrados incorporados en indumentaria y adornos, tales como los pectorales con las bandas cruzadas o el elemento $U$ en el tocado, actuaban como símbolos de estatus. Dentro del medio común, las vasijas cerámicas, el significado sagrado se une con la función práctica de los contenedores para todos los sectores sociales.

La diseminación de estos conceptos cosmológicos en la sociedad de San Lorenzo se logró mediante el uso común de las cerámicas decoradas con motivos sagrados. Estas vasijas constituían la manifestación tangible de la cosmología en el mundo cotidiano, en donde era posible así contemplar e imaginar los con-

66. John E. Clark, "Antecedentes de la cultura olmeca”, en Clark (comp.), op. cit., pp. 3I-4I.

67. Richard Lesure, "Vessel Form and Function in an Early Formative Ceramic Assemblage from Coastal Mexico", Journal of Field Archaeology, vol. 25, núm. I, 1998, pp. 19-36. 
ceptos y aun transmitirlos, a personas de diferentes edades y estatus. ${ }^{68} \mathrm{Su}$ uso confería un significado simbólico a varias actividades como la alimentación. Ya para II5o a.C., con el surgimiento de poderosos gobernantes en San Lorenzo, la creciente importancia de estas vasijas permitía infundir en la sociedad los conceptos cosmológicos necesarios para la dramaturgia del poder olmeca.

La introducción de la tensión ideológica en la sociedad mediante el uso de medios con valores inconmensurables (por ejemplo, piedra versus terracota) ayudó a impregnar en el lienzo social el mensaje de la unión de contrarios como el dominio divino y la subordinación, el privilegio y el compromiso, el poder y el deber. Las aspiraciones políticas de los gobernantes encontraron en esta unión el camino espiritual para perpetuar su autoridad divina. La diseminación de los conceptos sagrados a través del intercambio con regiones alejadas ofreció una plataforma común para la comunicación con grupos de tradiciones diversas. La traducción y aceptación de conceptos sagrados olmecas en estas sociedades alcanzó con el tiempo una plena fusión ideológica de lo local y lo ajeno que, al decaer el pueblo olmeca, enriqueció la cosmovisión de las civilizaciones ulteriores.

Agradecimientos. Es un placer reconocer la labor dedicada y entusiasta del equipo del Proyecto Arqueológico San Lorenzo Tenochtitlán (PASLT). En particular, quisiéramos agradecer a Marisol Varela Gómez su apoyo en la preparación de varias figuras y a Brizio Martínez la fotografía de los monumentos de San Lorenzo. El pAsLT ha contado con el generoso apoyo financiero de las siguientes instituciones y dependencias: el Instituto de Investigaciones Antropológicas y la Dirección General de Asuntos del Personal Académico de la Universidad Nacional Autónoma de México; The American Philosophical Society, el Consejo Nacional de Ciencia y Tecnología, The National Endowment for the Humanities, The National Geographic Society y The Foundation for the Advancement of Mesoamerican Studies. \$\$ 


\section{Bibliografia de las tablas}

Angulo, Jorge, "Observaciones sobre su pensamiento cosmogónico y la organización socipolítica”, en John Clark (ed.), Los olmecas en Mesoamérica, México, Citibank/El Equilibrista, 1994, pp. 223-238.

_- "The Chalcatzingo Reliefs: An Iconographic Analysis", en David C. Grove (ed.), Ancient Chalcatzingo, Austin, University of Texas Press, 1987, pp. I32-158. Ayala Falcón, Maricela, "Relaciones entre textos y dibujos en el Códice de Dresde", Estudios de Cultura Maya, vol. VII, I968, pp. 85-II3.

Boot, Eric, "The human hand in Classic Maya Hieroglypic Writing", www.mesoweb. com/features/boot, 2004.

Coe, Michael D., "The Olmec Style and Its Distribution", en Handbook of Middle American Indians, Archaeology of Southern Mesoamerica, editado por G.R. Willey, Austin, University of Texas Press, 1965, vol. 3, part 2, pp. 739-775.

Covarrubias, Miguel, Arte indígena de México y Centroamérica, México, Universidad Nacional Autónoma de México, ig6r.

Clewlow, Carl William Jr., A Stylistic and Chronological Study of Olmec Monumental Sculpture, Berkeley, Contributions of the University of California Archaeological Research Facility, 1974, núm. 4.

De la Fuente, Beatriz, Los hombres de piedra: escultura olmeca, México, Universidad Nacional Autónoma de México, 1984.

Drucker, Philip, La Venta, Tabasco, a Study of Olmec Ceramics and Art, Washington D.C., Smithsonian Institution Bureau of American Ethnology, Bulletin I53, I952. Flannery, Kent V. y Joyce Marcus, "Ancient Zapotec Ritual and Religion: An Application to the Direct Historical Approach", en Jaime Litvak y Lorena Mirambel (eds.), Arqueología, historia y antropología. In memoriam José Luis Lorenzo Bautista, México, Instituto Nacional de Antropología e Historia (Colección Científica 4I5), 2000, pp. 205-234.

—-, "Formative Mexican Chiefdoms and the Myth of "Mother Culture", Journal of Anthropological Archaeology, núm. 19, 2000, pp. I-37.

Joralemon, Peter D., A Study of Olmec Iconography, Studies in Pre-Columbian Art and Archaeology, Washington D.C., Dumbarton Oaks, núm. 7, I97I.

—. "The Olmec Dragon: A Study in Pre-Columbian Iconography", en H.B. Nicholson (coord.), Origins of Religious Art and Iconography in Preclassic Mesoamerica, Los Angeles, University of California (Latin American Studies Series, 3I), 1976, pp. 27-7I. 
Joyce, R. A. et al., "Olmec Bloodletting: An Iconographic Study, en M.G. Robertson (coord.), Sixth Palenque Round Table, I986, Norman, University of Oklahoma Press, I991, pp. I43-I50.

Ladrón de Guevara, Sara, "Las manos-insignia en la Cabeza 7 de San Lorenzo", Arqueología Mexicana. Veracruz, vol. XII, núm. 7I, 2005, pp. 34-4I.

Marcus, Joyce, "Zapotec Chiefdoms and the Nature of Formative Religions", en Robert Sharer y David C. Grove (comps.), Regional Perspectives on the Olmec, Nueva York, Cambridge University Press, 1989, pp. I48-197.

Muse, Michael y T. Stocker, "The cult of the cross", The Steward Anthropological Journal, vol. 5, núm. 2, I974, pp. 67-98.

Niederberger, Christine, Paléopaysages et Archéologie Pre-urbaine du Bassin de Mexico (Mexique), México, Centre d'Études Mexicaines et Centroamericaines (Études Mesoamericaines XI:I-II), I987.

Norman, W. Garth, "Izapa Sculpture”, part 2, Text, Papers of the New World Archaeological Foundation, Provo, Utah, Brigham Young University/ New World Archaeological Foundation, núm. 30, 1976.

Piña Chan, Román, El lenguaje de las piedras. Glifica olmeca y zapoteca, México, Fondo de Cultura Económica, 2002.

—, El pueblo del jaguar (los olmecas arqueológicos), México, Consejo para la planeación e instalación del Museo Nacional de Antropología, 1964.

—, Historia, arqueología y arte prehispánico, México, Fondo de Cultura Económica, 1972.

Quitarte, Jacinto, "Early Art Styles of Mesoamerica and Early Classic Maya Art", en Richard E. W. Adams (ed.), The Origins of Maya Civilization, Albuquerque, University of New Mexico Press, 1977.

Reilly III, Kent, "Cosmología, soberanismo y espacio ritual en la Mesoamérica del Formativo”, en J. Clark (ed.), Los olmecas en Mesoamérica, México, El Equilibrista/ Citbank, I994, pp. 239-260.

Stirling, Matthew W., "Monumental Sculpture of Southern Veracruz and Tabasco", en Hanbook of Middle American Indians, Austin, University of Texas Press, 1965, vol. 3, pp. 716-738.

Taube, Karl, "The Rainmakers: The Olmec and their Contributions to Mesoamerican Belief and Ritual", en The Olmec World, Ritual and Rulership, Princeton, Princeton University/The Art Museum, I995, pp. 83-I04.

Vogt, Evon Z., "Indian Crosses and Sceptres: the Results of Circumscribed Spanishindian Interaction in Mesoamerica", ponencia presentada en el Simposium In word and deed: interethnic images and responses in the New World, España, Trujillo, I988. 